\title{
AVALIAÇÃO DE TÉCNICAS PARA INDUÇÃO DA REGENERAÇÃO NATURAL EM ÁREA DE PRESERVAÇÃO PERMANENTE SOB USO ANTERIOR DO SOLO COM Pinus elliottii
}

\author{
Lauri Amândio Schorn ${ }^{1}$, Andres Krieger ${ }^{2}$, Marmonn Canestraro Nadolny ${ }^{3}$, \\ Tatiele Anete Bergamo Fenilli ${ }^{4}$ \\ ${ }^{1}$ Eng. Florestal, Dr., Depto. de Engenharia Florestal, FURB, Blumenau, SC, Brasil - lschorn@ furb.br \\ ${ }^{2}$ Graduando em Eng. Florestal, FURB, Blumenau, SC, Brasil \\ ${ }^{3}$ Eng. Florestal, M. Sc., Renova Floresta, Rio Negrinho, SC, Brasil - valorflorestal@matrix.com.br \\ ${ }^{4}$ Eng $^{\mathrm{a}}$ Agrônoma, Dr ${ }^{\mathrm{a}}$, Depto. de Engenharia Florestal, FURB, Blumenau, SC, Brasil - tfenilli@ furb.br \\ Recebido para publicação: 28/04/2009 - Aceito para publicação: 28/09/2009
}

\begin{abstract}
Resumo
Este trabalho teve como objetivos avaliar os efeitos de diferentes técnicas para indução da regeneração natural em uma área de preservação permanente, após o corte final de um povoamento de Pinus elliottii. O experimento foi instalado em dezembro de 2004, em uma fazenda da empresa Renova Floresta, no município de Rio Negrinho, estado de Santa Catarina. Foram estabelecidos sete tratamentos aplicando técnicas que visam acelerar o processo de restabelecimento da vegetação florestal. Em julho de 2008 foi realizada a amostragem da vegetação arbórea, nas áreas correspondentes aos tratamentos implantados, quando foram mensurados todos os indivíduos maiores que $0,20 \mathrm{~m}$ de altura. Foram avaliadas a estrutura horizontal, riqueza, diversidade, participação de grupos ecológicos e distribuição das alturas. Solanum variabile, Baccharis uncinela e Eupatorium compressum foram as espécies de maior frequência, densidade e importância na maioria dos tratamentos aplicados. A aplicação de chuva de sementes, transposição de solo e instalação de poleiros resultaram em densidades mais elevadas de plantas. A riqueza de espécies e a diversidade foram maiores nos tratamentos com plantio de enriquecimento, aplicação de chuva de sementes e instalação de poleiros artificiais. A densidade, diversidade e riqueza de espécies foram consideradas as variáveis mais adequadas para a avaliação da restauração ecológica.

Palavras-chave: Regeneração natural; floresta ciliar; restauração florestal.
\end{abstract}

\begin{abstract}
Evaluation of techniques for induction of regeneration in permanent preservation areas under former use of the soil with Pinus elliottii. This work aimed at evaluating the effects of seven techniques for natural regenerative induction in an area of permanent preservation, after the final cut of Pinus elliottii stand. The experiment was installed on a farm belonging to Renova Forest Co., in the municipality of Rio Negrinho, State of Santa Catarina on December 2004. Seven treatments were installed using techniques to speed up the forest vegetation restoration. On July 2008 tree sampling was done in the areas corresponding to the seven treatments, with measurement of all individuals higher than $0.20 \mathrm{~m}$. Evaluated aspects were the horizontal structure, richness, diversity, participation and distribution of ecological groups of heights. Solanum variabile, Uncinela Baccharis and Eupatorium compressun were the species of higher frequency, density and size in most treatments. The application of seed rain, soil transposition and the installation of perches resulted in higher plant densities. The richness of species and diversity were higher in treatments with enrichment planting, application of seed rain and installation of artificial perches. The density, diversity and species richness variables have been considered more appropriate for the evaluation of ecological restoration. Keywords: Natural regeneration; riparian forest; forest restoration.
\end{abstract}

\section{INTRODUÇÃO}

A técnica de restauração comumente utilizada e muitas vezes solicitada pelos órgãos ambientais resume-se no plantio de mudas de espécies florestais nativas. No entanto, com essa opção, muitas vezes não são restabelecidas as funções ecológicas e relações interespecíficas, devido principalmente ao 
reduzido número de espécies utilizadas e mantidas nessas áreas ou pela má escolha das espécies. Além disso, a restauração através de plantio de mudas em geral apresenta custos relativamente elevados, quando comparados com outros processos de aceleração da regeneração natural.

Neste sentido, Reis (2006) descreve que "atingir o mais próximo possível de sua condição original significa trazer novamente ao ambiente espécies e interações existentes entre elas". Isso, evidentemente, não pode ser predefinido dentro de um espaço de tempo por executores de projetos de restauração, mas apenas previstas as probabilidades de um dia se alcançar a semelhança com o ecossistema original. Mais do que a proximidade à condição anterior, níveis de sucessão ecológica devem ser alcançados, os quais atendem ao conceito de estabilidade (resiliência, persistência, resistência, variabilidade) proposto por Pimm (1991).

Rodrigues; Gandolfi (2000) relataram que as possibilidades e pretensões de projetos de restauração de áreas degradadas, onde a matriz regional ainda é florestal, são muito distintas dos projetos propostos para locais onde a matriz não é mais florestal. No primeiro caso, a restauração depende basicamente de se criarem condições necessárias para a chegada e estabelecimento de diásporos oriundos das áreas florestais do entorno. Nas situações onde a matriz regional também se constitui como áreas fortemente alteradas ou degradadas, o próprio projeto de restauração deve prever estratégias que garantam a implantação e perpetuação das características naturais da vegetação restaurada, como biodiversidade elevada e complexidade de interações, sem contar com os possíveis aportes de diásporos e de variabilidade genética das áreas vizinhas.

Mais recentemente, alguns autores (REIS et al., 2003; BECHARA, 2006) citaram a nucleação como um princípio sucessional na colonização natural de áreas em formação. É entendida como a capacidade de uma espécie de propiciar uma significativa melhoria na qualidade ambiental, permitindo um aumento na probabilidade de ocupação desse ambiente por outras espécies (YARRANTON; MORRISON, 1974).

As atividades de restauração, baseadas no processo ecológico de nucleação, foram denominadas por Reis et al. (2003) de "técnicas nucleadoras de restauração". São consideradas como técnicas nucleadoras: a) formação de coberturas de solo através de semeadura direta de espécies herbáceoarbustivas; b) formação de abrigos artificiais, através do enleiramento de galharias; c) transposição de chuvas de sementes; d) transposição de solo; e) instalação de poleiros artificiais; f) plantio de mudas de espécies arbóreas em grupos de Anderson (BECHARA, 2006).

Alvarenga et al. (2006) também relataram que uma das alternativas para a recomposição da vegetação é a condução da regeneração natural, que em muitos casos apresenta-se como uma das alternativas mais promissoras, em função dos aspectos ecológico, silvicultural e econômico. Segundo Botelho; Davide (2002), a condução da regeneração natural, por exigir menos mão de obra e insumos, pode reduzir, significativamente, o custo de implantação de uma floresta de proteção.

A diversidade da vegetação em áreas ribeirinhas está relacionada com uma intrincada conjunção hidro-geomorfológica. A distribuição das espécies e das comunidades nessas áreas reflete a sensibilidade da vegetação às características abióticas, muitas vezes restritivas, desse meio (BARDDAL, 2002). Como exemplo, pode-se mencionar que, em ambientes de maior saturação hídrica, a regeneração natural se caracteriza por menor diversidade e menores alturas e diâmetros, conforme constataram Barddal et al. (2004). Nesse sentido, verifica-se que as zonas ripárias apresentam fragilidades e são dotadas de complexidade que exige cuidados maiores na restauração, os quais devem contemplar suas variações biofísicas, assim como técnicas que permitam que as interações entre espécies e entre espécies e o meio abiótico sejam restabelecidas de forma mais natural, como as técnicas nucleadoras preconizam.

Os povoamentos florestais implantados no Brasil nas últimas décadas abrangeram muitas áreas consideradas de preservação permanente, de acordo com a Lei $n^{\circ}$ 4.771/65 e suas alterações (BRASIL, 2009). Por ocasião da rotação dessas florestas e em atendimento às determinações legais, os proprietários necessitam realizar a restauração da vegetação natural nessas áreas, mas em geral os métodos de restauração têm contemplado apenas o seu isolamento e plantio de mudas, como usualmente feito.

Este trabalho teve como objetivo avaliar os efeitos, quanto à diversidade e à composição fitossociológica, de sete métodos para indução da regeneração natural em uma área de preservação permanente caracterizada como floresta fluvial, após a retirada de um povoamento de Pinus eliottii.

\section{MATERIAL E MÉTODOS}

O experimento foi instalado em dezembro de 2004, em uma fazenda da empresa Renova Floresta, no município de Rio Negrinho, situado no planalto norte do estado de Santa Catarina. 
$\mathrm{O}$ clima na região é caracterizado como $\mathrm{Cfb}$ (mesotérmico, subtropical úmido, com verões frescos, sem estação seca e com geadas severas frequentes), segundo a classificação de Köeppen (GAPLAN, 1986). No âmbito geológico, a região é constituída de rochas sedimentares paleozoicas (KOBIYAMA et al., 2007). O relevo regional é suave ondulado a ondulado. Os solos da área estudada são classificados como CAMBISSOLO HÁPLICO Alítico, e variam de rasos a profundos, possuindo sequência de horizonte $\mathrm{A}, \mathrm{Bi}, \mathrm{C}$, com diferenciação de horizontes visualmente modesta. $\mathrm{O}$ horizonte $\mathrm{B}$ apresenta cores amareladas e brunadas, com matiz de 5 a 10 YR. A análise química do solo apresentou os seguintes parâmetros: textura $29 \%$ de argila; $\mathrm{pH} 3,80$; matéria orgânica $6,00 \%$; fósforo $5,50 \mathrm{ppm}$; potássio 32,00 ppm; alumínio 7,30 $\mathrm{cmol}_{\mathcal{c}} / 1$; cálcio $0,80 \mathrm{cmol}_{\mathrm{c}} / \mathrm{l}$; magnésio $0,40 \mathrm{cmol}_{\mathrm{c}} / \mathrm{l} ; \mathrm{H}+\mathrm{Al}$ 43,35 $\mathrm{cmol}_{\mathrm{c}} \mathrm{l}$; CTC 44,64 $\mathrm{cmol}_{\mathrm{c}} / \mathrm{l}$ e saturação por bases 2,89\%.

Foram implantados sete tratamentos, aplicando-se técnicas que visavam acelerar o processo de restabelecimento da vegetação arbórea: T0 - Testemunha: abandono da área; T1 - Ativação do banco de sementes: consistiu no revolvimento do solo em pontos onde não havia regeneração de espécies nativas ou onde a regeneração era considerada muito incipiente. Para tanto, foi realizando o revolvimento em coroas com $80 \mathrm{~cm}$ de diâmetro, sem retirar o material sobre o solo; T2 - Semeadura direta: nesse método, foi realizada a semeadura direta a lanço de bracatinga (Mimosa scabrella), utilizando-se a densidade de $1 \mathrm{~kg}$ de sementes.ha ${ }^{-1}$ ou $0,1 \mathrm{~g}$ de sementes $/ \mathrm{m}^{2}$; T3 - Chuva de sementes: é composta por todas as sementes que chegam a um local, trazidas pelos agentes bióticos e abióticos. Neste trabalho, a chuva de sementes foi coletada em dez coletores de tela plástica de $1 \mathrm{~m} \times 1 \mathrm{~m}$, colocados em áreas de floresta nativa, com recolhimento do material mensalmente, durante um ano. O material colhido foi depositado em trinta coroas com $80 \mathrm{~cm}$ de diâmetro, abertas na vegetação rasteira sem a realização de qualquer cobertura; T4 Poleiros artificiais: consiste na instalação de poleiros artificiais, com o objetivo de atrair a avifauna. Nesses locais, a atividade de defecação resulta em semeadura na área abaixo do poleiro. Foram montados três poleiros, com altura de 8 metros, utilizando-se taquaras e galhos secos; T5 - Transposição de solo: nesse método, foram retiradas a serapilheira e a camada superficial do solo com $10 \mathrm{~cm}$ de profundidade em alguns pontos em área de floresta nativa, as quais foram recolocadas na área a recuperar. Foram instalados trinta pontos de transposição do solo, onde o material foi depositado e esparramado em coroas com $80 \mathrm{~cm}$ de diâmetro; T6 - Plantio de enriquecimento: consistiu no plantio de mudas das espécies arbóreas nativas nos locais onde não havia regeneração de espécies arbóreas. O critério utilizado para a seleção das espécies foi a ocorrência em ambiente ciliar, na região de realização do estudo. Foram utilizadas: Parapiptadenia rigida (01), Psidium cattleianum (04), Schinus molle (03), Araucaria angustifolia (04), Mimosa scabrella (04), Cedrela fissilis (03), Ocotea porosa (03), Cordia trichotoma (02), Dalbergia brasiliensis (03), Vitex montevidensis (03). As mudas foram distribuídas e plantadas aleatoriamente, resultando em um espaçamento médio de 2,5 metros entre plantas na área, não havendo a eliminação da vegetação herbáceo-arbustiva.

Os tratamentos foram instalados em uma área contínua situada na margem de um córrego. Cada tratamento abrangeu uma área de $300 \mathrm{~m}^{2}(10 \times 30 \mathrm{~m})$, posicionada com 30 metros perpendicularmente ao córrego e paralelamente aos demais tratamentos. O córrego se caracteriza pela largura média de 2,0 metros, apresentando leito encaixado e baixa declividade em suas margens. A cobertura vegetal na área experimental, após a extração do povoamento de Pinus elliottii, era constituída de vegetação herbácea, com predominância de gramíneas. Em cada área de tratamento, foram locadas três parcelas amostrais de 1 x $30 \mathrm{~m}\left(30 \mathrm{~m}^{2}\right)$, distribuídas de forma paralela e sistemática, totalizando $90 \mathrm{~m}^{2}$ de amostragem.

Em julho de 2008, foi realizada a amostragem da vegetação arbustiva e arbórea, nas áreas correspondentes aos sete tratamentos implantados. Foram amostrados todos os indivíduos maiores que $0,20 \mathrm{~m}$ de altura, os quais foram divididos em dois estratos: I - altura $>0,20 \mathrm{~m}<3 \mathrm{~m}$; e II - $\geq 3 \mathrm{~m}$ de altura.

Foram mensuradas as seguintes variáveis nos indivíduos: altura, diâmetro à altura do colo (DAC) no estrato I; circunferência na altura do peito (CAP) no estrato II. Dos indivíduos ingressantes, foi coletado material fértil ou não, e levado ao herbário do Departamento de Engenharia Florestal da FURB (Universidade de Blumenau), onde as plantas foram identificadas e depositadas.

Para cada um dos tratamentos, foram calculados os parâmetros fitossociológicos absolutos e relativos, de densidade, dominância e frequência, e de valor de importância, conforme Finol (1971). Os dados de densidade (indivíduos.ha $\left.{ }^{-1}\right)$ e a área basal $\left(\mathrm{m}^{2} \cdot \mathrm{ha}^{-1}\right)$ tiveram suas médias submetidas à análise de variância e comparadas pelo teste de Tukey ao nível de 5\% de probabilidade. Foi determinada a riqueza específica, a diversidade pelo método de Shannon (BROWER; ZAR, 1984) e a distribuição das espécies 
em grupos ecológicos para a vegetação em cada tratamento. Para a classificação sucessional das espécies em grupos ecológicos, foi utilizada a metodologia proposta por Swaine; Whitmore (1988), com as alterações sugeridas por Oliveira-Filho (1994), agrupando-se as espécies em pioneiras, climácicas exigentes em luz e climácicas tolerantes à sombra.

\section{RESULTADOS E DISCUSSÕES}

$\mathrm{Na}$ totalidade dos tratamentos, foram encontradas 40 espécies arbóreas, arbustivas e herbáceas, pertencentes a 19 famílias, em um total de 863 indivíduos amostrados, com 639 indivíduos no estrato I e 224 indivíduos no estrato II.

Algumas espécies apresentaram maiores valores de importância em determinados tratamentos, como é o caso de Solanum variabile e de Baccharis uncinella, que estão entre as três espécies mais importantes nos tratamentos de abandono da área e de ativação do banco de sementes. De forma semelhante, Eupatorium compressum também está entre as três espécies mais importantes em seis dos sete tratamentos, sendo acompanhada por Croton sp. em cinco desse tratamentos (Tabela 1). Esses resultados mostram que as espécies citadas, que ocorrem com elevada densidade e apresentam elevada importância, sofreram pouca influência dos tratamentos aplicados. Além disso, esse grupo de espécies é composto por herbáceas e arbustivas, evidenciando maior eficiência de ingresso através de vetores naturais de dispersão, quando comparadas com espécies arbóreas. Exceção a isso foi verificada nos tratamentos de semeadura direta e de transposição de solo, onde Mimosa scabrella destacou-se em densidade e importância, resultado associado à eficiência do ingresso dessa espécie por meio dos dois tratamentos. A elevada densidade dessa espécie no tratamento com transposição de solo sugere que o material transposto apresentava considerável abundância de sementes de Mimosa scabrella, oriunda do banco de sementes formado no solo da floresta em fases sucessionais iniciais.

Tabela 1. Parâmetros fitossociológicos absolutos e relativos em sete tratamentos para restauração da vegetação natural em Rio Negrinho $(\mathrm{SC})$. VI = Valor de importância; GE = Grupo ecológico; $\mathrm{P}=$ Pioneira; $\mathrm{CL}=$ Climácica exigente em luz; $\mathrm{CS}=$ Climácica tolerante à sombra.

Table 1. Species phytosociological parameters in seven restoration natural vegetation treatments at Rio Negrinho (SC). VI - Importance value; GE - Ecological group; P - Pionner; CL - Climax light demanding; CS - Climax shaad tolerant.

\begin{tabular}{|c|c|c|c|c|c|c|c|c|c|}
\hline \multirow[b]{2}{*}{ Nome científico } & \multicolumn{2}{|c|}{ Densidade } & \multicolumn{2}{|c|}{ Dominância } & \multicolumn{2}{|c|}{ Frequência } & \multicolumn{2}{|c|}{ VI } & \multirow[b]{2}{*}{ GE } \\
\hline & $\begin{array}{c}\text { Abs. } \\
(\text { n.ha } \\
\text {-1 })\end{array}$ & Rel. $(\%)$ & $\begin{array}{c}\text { Abs. } \\
\left(\mathbf{m}^{2} \cdot \mathbf{h a}^{-1}\right)\end{array}$ & $\begin{array}{l}\text { Rel. } \\
(\%)\end{array}$ & Abs. & $\begin{array}{l}\text { Rel. } \\
(\%)\end{array}$ & Abs. & Rel. (\%) & \\
\hline \multicolumn{10}{|c|}{ T0 - Testemunha - abandono da área } \\
\hline Solanum variabile Mart. & 5888,89 & 44,92 & 1,726 & 31,41 & 1,00 & 12,00 & 88,32 & 29,44 & $\mathrm{P}$ \\
\hline Eupatorium compressum Gardner & 777,78 & 5,93 & 2,092 & 38,07 & 1,00 & 12,00 & 56,01 & 18,67 & $\mathrm{P}$ \\
\hline Baccharis uncinella DC. & 1777,78 & 13,56 & 1,025 & 18,66 & 1,00 & 12,00 & 44,21 & 14,74 & $\mathrm{P}$ \\
\hline Croton sp. & 888,89 & 6,78 & 0,330 & 6,00 & 0,67 & 8,00 & 20,78 & 6,93 & $\mathrm{P}$ \\
\hline Asclepias sp. & 1000,00 & 7,63 & 0,060 & 1,10 & 0,67 & 8,00 & 16,73 & 5,58 & $\mathrm{P}$ \\
\hline Ocotea pulchella (Nees) Mez & 777,78 & 5,93 & 0,008 & 0,14 & 0,67 & 8,00 & 14,07 & 4,69 & CS \\
\hline $\begin{array}{l}\text { Myrsine coriacea }(\mathrm{Sw} .) \mathrm{R} . \mathrm{Br} \text {. ex } \\
\text { Roem. }\end{array}$ & 666,67 & 5,08 & 0,045 & 0,82 & 0,67 & 8,00 & 13,90 & 4,63 & $\mathrm{P}$ \\
\hline Cinnamomum sellowianum Angely & 333,33 & 2,54 & 0,048 & 0,87 & 0,67 & 8,00 & 11,42 & 3,81 & CS \\
\hline Clethra scabra Pers. & 333,33 & 2,54 & 0,083 & 1,51 & 0,33 & 4,00 & 8,05 & 2,68 & $\mathrm{CL}$ \\
\hline $\begin{array}{l}\text { Grazielia serrata (Spr.) R. M. King \& } \\
\text { H. Rob. }\end{array}$ & 111,11 & 0,85 & 0,057 & 1,03 & 0,33 & 4,00 & 5,88 & 1,96 & $\mathrm{P}$ \\
\hline Calyptranthes concinna DC. & 222,22 & 1,69 & 0,005 & 0,09 & 0,33 & 4,00 & 5,79 & 1,93 & CS \\
\hline Piptocarpha organensis Cabrera & 111,11 & 0,85 & 0,015 & 0,27 & 0,33 & 4,00 & 5,12 & 1,71 & $\mathrm{P}$ \\
\hline Schinus terebinthifolius Raddi & 111,11 & 0,85 & 0,001 & 0,03 & 0,33 & 4,00 & 4,87 & 1,62 & $\mathrm{CL}$ \\
\hline Myrcia hatschbachii D. Legrand & 111,11 & 0,85 & 0,004 & 0,01 & 0,33 & 4,00 & 4,86 & 1,62 & $\mathrm{CL}$ \\
\hline Total & 13111,11 & 100,00 & 5,499 & 100,01 & 8,33 & 100,00 & 300,01 & 100,01 & \\
\hline \multicolumn{10}{|c|}{ T1 - Ativação do banco de sementes no solo } \\
\hline Baccharis uncinella DC. & 1777,78 & 17,02 & 1,502 & 40,41 & 1,00 & 13,64 & 71,07 & 23,69 & $\mathrm{P}$ \\
\hline Solanum variabile Mart. & 3000,00 & 28,72 & 0,917 & 24,67 & 1,00 & 13,64 & 67,03 & 22,34 & $\mathrm{P}$ \\
\hline
\end{tabular}




\begin{tabular}{|c|c|c|c|c|c|c|c|c|c|}
\hline Croton sp. & 2555,56 & 24,47 & 0,606 & 16,30 & 1,00 & 13,64 & 54,41 & 18,14 & $\mathrm{P}$ \\
\hline Eupatorium compressum Gardner & 444,44 & 4,26 & 0,573 & 15,41 & 1,00 & 13,64 & 33,31 & 11,10 & $\mathrm{P}$ \\
\hline Asclepias sp. & 1333,33 & 12,77 & 0,072 & 1,93 & 0,67 & 9,09 & 23,78 & 7,93 & $\mathrm{P}$ \\
\hline $\begin{array}{l}\text { Myrsine coriacea (Sw.) R. Br. ex } \\
\text { Roem. }\end{array}$ & 444,44 & 4,26 & 0,017 & 0,45 & 0,67 & 9,09 & 13,80 & 4,60 & $\mathrm{P}$ \\
\hline Piptocarpha organensis Cabrera & 222,22 & 2,13 & 0,018 & 0,49 & 0,67 & 9,09 & 11,71 & 3,90 & $\mathrm{P}$ \\
\hline Solanum sp. & 222,22 & 2,13 & 0,007 & 0,18 & 0,33 & 4,55 & 6,85 & 2,28 & $\mathrm{P}$ \\
\hline Ilex dumosa Reissek & 222,22 & 2,13 & 0,003 & 0,07 & 0,33 & 4,55 & 6,74 & 2,25 & CS \\
\hline $\begin{array}{l}\text { Nectandra megapotamica (Spreng.) } \\
\text { Mez }\end{array}$ & 111,11 & 1,06 & 0,003 & 0,08 & 0,33 & 4,55 & 5,69 & 1,90 & CS \\
\hline Schinus terebinthifolius Raddi & 111,11 & 1,06 & 0,001 & 0,01 & 0,33 & 4,55 & 5,62 & 1,87 & $\mathrm{CL}$ \\
\hline Total & 10444,43 & 100,01 & 3,719 & 100,00 & 7,33 & 100,03 & 300,01 & 100,00 & \\
\hline \multicolumn{10}{|c|}{ T2 - Semeadura direta de Mimosa scabrella } \\
\hline Mimosa scabrella Benth. & 4777,78 & 40,95 & 9,342 & 81,60 & 1,00 & 10,34 & 132,90 & 44,30 & $\mathrm{P}$ \\
\hline Eupatorium compressum Gardner & 888,89 & 7,62 & 0,715 & 6,25 & 1,00 & 10,34 & 24,21 & 8,07 & $\mathrm{P}$ \\
\hline Solanum variabile Mart. & 1333,33 & 11,43 & 0,162 & 1,41 & 1,00 & 10,34 & 23,19 & 7,73 & $\mathrm{P}$ \\
\hline Cinnamomum sellowianum Angely & 777,78 & 6,67 & 0,272 & 2,37 & 0,67 & 6,90 & 15,94 & 5,31 & $\mathrm{CS}$ \\
\hline $\begin{array}{l}\text { Myrsine coriacea }(\mathrm{Sw} .) \mathrm{R} . \text { Br. ex } \\
\text { Roem. }\end{array}$ & 555,56 & 4,76 & 0,013 & 0,11 & 1,00 & 10,34 & 15,22 & 5,07 & $\mathrm{P}$ \\
\hline Croton sp. & 777,78 & 6,67 & 0,099 & 0,87 & 0,67 & 6,90 & 14,43 & 4,81 & $\mathrm{P}$ \\
\hline Baccharis uncinella DC. & 666,67 & 5,71 & 0,122 & 1,07 & 0,67 & 6,90 & 13,68 & 4,56 & $\mathrm{P}$ \\
\hline Asclepias sp. & 555,56 & 4,76 & 0,022 & 0,19 & 0,67 & 6,90 & 11,85 & 3,95 & $\mathrm{P}$ \\
\hline Solanum lacerdae Dusén & 444,44 & 3,81 & 0,046 & 0,40 & 0,67 & 6,90 & 11,11 & 3,70 & $\mathrm{P}$ \\
\hline Dicksonia sellowiana Hook. & 111,11 & 0,95 & 0,556 & 4,85 & 0,33 & 3,45 & 9,26 & 3,09 & $\mathrm{CS}$ \\
\hline $\begin{array}{l}\text { Nectandra megapotamica (Spreng.) } \\
\text { Mez }\end{array}$ & 222,22 & 1,90 & 0,002 & 0,02 & 0,33 & 3,45 & 5,37 & 1,79 & $\mathrm{CS}$ \\
\hline $\begin{array}{l}\text { Grazielia serrata (Spr) R.M. King \& } \\
\text { H. Rob. }\end{array}$ & 111,11 & 0,95 & 0,088 & 0,77 & 0,33 & 3,45 & 5,17 & 1,72 & $\mathrm{P}$ \\
\hline Ilex theezans Mart. & 111,11 & 0,95 & 0,007 & 0,06 & 0,33 & 3,45 & 4,46 & 1,49 & $\mathrm{CS}$ \\
\hline Piptocarpha axillaris (Less.) Baker & 111,11 & 0,95 & 0,001 & 0,01 & 0,33 & 3,45 & 4,41 & 1,47 & $\mathrm{P}$ \\
\hline Rhamnus sphaerosperma $\mathrm{Sw}$. & 111,11 & 0,95 & 0,0004 & 0,004 & 0,33 & 3,45 & 4,40 & 1,47 & $\mathrm{P}$ \\
\hline Ilex paraguariensis A. St.-Hil. & 111,11 & 0,95 & 0,0003 & 0,003 & 0,33 & 3,45 & 4,40 & 1,47 & CS \\
\hline Total & 11666,67 & 99,98 & 11,448 & 100,00 & 9,66 & 100,01 & 300,00 & 100,00 & \\
\hline \multicolumn{10}{|c|}{ T3 - Aplicação de chuva de sementes } \\
\hline Eupatorium compressum Gardner & 2666,67 & 15,69 & 2,2880 & 45,74 & 1,00 & 9,38 & 70,80 & 23,60 & $\mathrm{P}$ \\
\hline Croton sp. & 3333,33 & 19,61 & 0,7915 & 15,82 & 1,00 & 9,38 & 44,81 & 14,94 & $\mathrm{P}$ \\
\hline $\begin{array}{l}\text { Myrsine coriacea }(\mathrm{Sw} .) \mathrm{R} . \mathrm{Br} \text {. ex } \\
\text { Roem. }\end{array}$ & 4000,00 & 23,53 & 0,2082 & 4,16 & 1,00 & 9,38 & 37,07 & 12,36 & $\mathrm{P}$ \\
\hline Baccharis uncinella DC. & 1666,67 & 9,80 & 0,5301 & 10,60 & 1,00 & 9,38 & 29,78 & 9,93 & $\mathrm{P}$ \\
\hline Solanum variabile Mart. & 1555,56 & 9,15 & 0,4548 & 9,09 & 1,00 & 9,38 & 27,62 & 9,21 & $\mathrm{P}$ \\
\hline Asclepias sp. & 888,89 & 5,23 & 0,0225 & 0,45 & 1,00 & 9,38 & 15,05 & 5,02 & $\mathrm{P}$ \\
\hline Ilex paraguariensis A. St.-Hil. & 555,56 & 3,27 & 0,1939 & 3,88 & 0,67 & 6,25 & 13,40 & 4,47 & CS \\
\hline Calyptranthes concinna DC. & 222,22 & 1,31 & 0,0623 & 1,25 & 0,67 & 6,25 & 8,80 & 2,93 & CS \\
\hline Matayba elaegnoides Radlk. & 222,22 & 1,31 & 0,0179 & 0,36 & 0,67 & 6,25 & 7,91 & 2,64 & $\mathrm{CL}$ \\
\hline $\begin{array}{l}\text { Cinnamomum amoenum (Nees) } \\
\text { Kosterm. }\end{array}$ & 444,44 & 2,61 & 0,0674 & 1,35 & 0,33 & 3,13 & 7,09 & 2,36 & CS \\
\hline Myrcia palustris DC. & 111,11 & 0,65 & 0,1554 & 3,11 & 0,33 & 3,13 & 6,89 & 2,30 & $\mathrm{CS}$ \\
\hline $\begin{array}{l}\text { Grazielia serrata (Spr.) R. M. King \& } \\
\text { H. Rob. }\end{array}$ & 333,33 & 1,96 & 0,0721 & 1,44 & 0,33 & 3,13 & 6,53 & 2,18 & $\mathrm{P}$ \\
\hline $\begin{array}{l}\text { Piptocarpha angustifolia Dusén ex } \\
\text { Malme }\end{array}$ & 444,44 & 2,61 & 0,0152 & 0,30 & 0,33 & 3,13 & 6,04 & 2,01 & $\mathrm{P}$ \\
\hline Piptocarpha axillaris (Less.) Baker & 111,11 & 0,65 & 0,1039 & 2,08 & 0,33 & 3,13 & 5,86 & 1,95 & $\mathrm{P}$ \\
\hline Cinnamomum sellowianum Angely & 222,22 & 1,31 & 0,0031 & 0,06 & 0,33 & 3,13 & 4,49 & 1,50 & $\mathrm{CS}$ \\
\hline $\begin{array}{l}\text { Nectandra megapotamica (Spreng.) } \\
\text { Mez }\end{array}$ & 111,11 & 0,65 & 0,0147 & 0,29 & 0,33 & 3,13 & 4,07 & 1,36 & CS \\
\hline Ilex theezans Mart. & 111,11 & 0,65 & 0,0009 & 0,02 & 0,33 & 3,13 & 3,80 & 1,27 & CS \\
\hline Total & 17000,00 & 99,99 & 5,0019 & 100,00 & 10,65 & 100,07 & 300,01 & 100,03 & \\
\hline \multicolumn{10}{|c|}{ T4 - Instalação de poleiros artificiais } \\
\hline Eupatorium compressum Gardner & 1444,44 & 9,77 & 1,711 & 30,47 & 1,00 & 8,57 & 48,82 & 16,27 & $\mathrm{P}$ \\
\hline Croton sp. & 2222,22 & 15,04 & 0,818 & 14,57 & 1,00 & 8,57 & 38,17 & 12,72 & $\mathrm{P}$ \\
\hline
\end{tabular}

FLORESTA, Curitiba, PR, v. 40, n. 2, p. 281-294, abr./jun. 2010. 


\begin{tabular}{|c|c|c|c|c|c|c|c|c|c|}
\hline $\begin{array}{l}\text { Cinnamomum amoenum (Nees) } \\
\text { Kosterm. }\end{array}$ & 1666,67 & 11,28 & 0,755 & 13,44 & 0,67 & 5,71 & 30,43 & 10,14 & CS \\
\hline Solanum variabile Mart. & 1444,44 & 9,77 & 0,477 & 8,49 & 1,00 & 8,57 & 26,84 & 8,95 & $\mathrm{P}$ \\
\hline Asclepias sp. & 1888,89 & 12,78 & 0,137 & 2,43 & 1,00 & 8,57 & 23,79 & 7,93 & $\mathrm{P}$ \\
\hline Baccharis uncinella DC. & 888,89 & 6,02 & 0,272 & 4,84 & 1,00 & 8,57 & 19,42 & 6,47 & $\mathrm{P}$ \\
\hline Solanum paranense Dusén & 1444,44 & 9,77 & 0,134 & 2,39 & 0,67 & 5,71 & 17,88 & 5,96 & $\mathrm{P}$ \\
\hline Myrcia palustris DC. & 888,89 & 6,02 & 0,288 & 5,13 & 0,67 & 5,71 & 16,86 & 5,62 & CS \\
\hline Cinnamomum sellowianum Angely & 555,56 & 3,76 & 0,410 & 7,30 & 0,67 & 5,71 & 16,77 & 5,59 & CS \\
\hline Solanum verbascifolium C. B. Wright & 555,56 & 3,76 & 0,353 & 6,29 & 0,33 & 2,86 & 12,91 & 4,30 & $\mathrm{P}$ \\
\hline Myrsine umbellata Mart. & 555,56 & 3,76 & 0,014 & 0,25 & 1,00 & 8,57 & 12,59 & 4,20 & $\mathrm{CL}$ \\
\hline $\begin{array}{l}\text { Myrsine coriacea }(\mathrm{Sw} .) \mathrm{R} . \mathrm{Br} \text {. ex } \\
\text { Roem. }\end{array}$ & 222,22 & 1,50 & 0,017 & 0,30 & 0,67 & 5,71 & 7,51 & 2,50 & $\mathrm{P}$ \\
\hline $\begin{array}{l}\text { Grazielia serrata (Spreng.) R. M. King } \\
\& \text { H. Rob. }\end{array}$ & 222,22 & 1,50 & 0,070 & 1,25 & 0,33 & 2,86 & 5,62 & 1,87 & $\mathrm{P}$ \\
\hline $\begin{array}{l}\text { Miconia hiemalis A. St.-Hil. \& Naudin } \\
\text { ex N. }\end{array}$ & 222,22 & 1,50 & 0,028 & 0,49 & 0,33 & 2,86 & 4,85 & 1,62 & $\mathrm{P}$ \\
\hline Mimosa scabrella Benth. & 111,11 & 0,75 & 0,057 & 1,01 & 0,33 & 2,86 & 4,62 & 1,54 & $\mathrm{P}$ \\
\hline Ilex theezans Mart. & 111,11 & 0,75 & 0,047 & 0,83 & 0,33 & 2,86 & 4,44 & 1,48 & CS \\
\hline Ocotea puberula (Rich.) Nees & 222,22 & 1,50 & 0,003 & 0,06 & 0,33 & 2,86 & 4,42 & 1,47 & $\mathrm{P}$ \\
\hline Campomanesia xanthocarpa O. Berg & 111,11 & 0,75 & 0,026 & 0,46 & 0,33 & 2,86 & 4,07 & 1,36 & CS \\
\hline Total & 14777,77 & 99,98 & 5,617 & 100,00 & 11,66 & 99,99 & 300,01 & 99,99 & \\
\hline \multicolumn{10}{|c|}{ T5 - Transposição de solo } \\
\hline Eupatorium compressum Gardner & 2444,44 & 14,97 & 2,414 & 33,25 & 1,00 & 9,09 & 57,31 & 19,10 & $\mathrm{P} ?$ \\
\hline Croton sp. & 4111,11 & 25,17 & 1,061 & 14,62 & 1,00 & 9,09 & 48,88 & 16,29 & $\mathrm{P}$ \\
\hline Mimosa scabrella Benth. & 2222,22 & 13,61 & 1,445 & 19,90 & 1,00 & 9,09 & 42,60 & 14,20 & $\mathrm{P}$ \\
\hline Asclepias sp. & 1888,89 & 11,56 & 0,078 & 1,08 & 1,00 & 9,09 & 21,73 & 7,24 & $\mathrm{P}$ \\
\hline Baccharis uncinella DC. & 1111,11 & 6,80 & 0,359 & 4,94 & 1,00 & 9,09 & 20,84 & 6,95 & $\mathrm{P}$ \\
\hline $\begin{array}{l}\text { Cinnamomum amoenum (Nees) } \\
\text { Kosterm. }\end{array}$ & 1333,33 & 8,16 & 0,193 & 2,66 & 1,00 & 9,09 & 19,91 & 6,64 & CS \\
\hline Solanum variabile Mart. & 888,89 & 5,44 & 0,208 & 2,86 & 1,00 & 9,09 & 17,39 & 5,80 & $\mathrm{P}$ \\
\hline Clethra scabra Pers. & 444,44 & 2,72 & 0,618 & 8,51 & 0,67 & 6,06 & 17,29 & 5,76 & $\mathrm{CL}$ \\
\hline Ilex paraguariensis A. St.-Hil. & 222,22 & 1,36 & 0,475 & 6,54 & 0,67 & 6,06 & 13,96 & 4,65 & $\mathrm{CS}$ \\
\hline $\begin{array}{l}\text { Cinnamomum glaziovii }(\mathrm{Mez}) \\
\text { Kosterm. }\end{array}$ & 555,56 & 3,40 & 0,235 & 3,24 & 0,33 & 3,03 & 9,67 & 3,22 & $\mathrm{CS}$ \\
\hline $\begin{array}{l}\text { Myrsine coriacea }(\mathrm{Sw} .) \mathrm{R} . \mathrm{Br} \text {. Ex } \\
\text { Roem. }\end{array}$ & 222,22 & 1,36 & 0,007 & 0,09 & 0,67 & 6,06 & 7,52 & 2,51 & $\mathrm{P}$ \\
\hline Myrsine umbellata Mart. & 333,33 & 2,04 & 0,024 & 0,33 & 0,33 & 3,03 & 5,40 & 1,80 & $\mathrm{CL}$ \\
\hline $\begin{array}{l}\text { Grazielia serrata (Spr.) R. M. King \& } \\
\text { H. Rob. }\end{array}$ & 222,22 & 1,36 & 0,019 & 0,26 & 0,33 & 3,03 & 4,65 & 1,55 & $\mathrm{P}$ \\
\hline Myrcia palustris DC. & 111,11 & 0,68 & 0,058 & 0,79 & 0,33 & 3,03 & 4,50 & 1,50 & CS \\
\hline Ocotea pulchella (Nees) Mez & 111,11 & 0,68 & 0,056 & 0,77 & 0,33 & 3,03 & 4,48 & 1,49 & CS \\
\hline $\begin{array}{l}\text { Piptocarpha angustifolia Dusén ex } \\
\text { Malme }\end{array}$ & 111,11 & 0,68 & 0,012 & 0,17 & 0,33 & 3,03 & 3,88 & 1,29 & $\mathrm{P}$ \\
\hline Total & 16333,31 & 99,99 & 7,262 & 100,01 & 10,99 & 99,99 & 300,01 & 99,99 & \\
\hline \multicolumn{10}{|c|}{ T6 - Plantio de enriquecimento } \\
\hline Croton sp. & 4333,33 & 34,51 & 1,138 & 23,32 & 1,00 & 9,09 & 66,92 & 22,31 & $\mathrm{P}$ \\
\hline Eupatorium compressum Gardner & 1777,78 & 14,16 & 1,497 & 30,67 & 1,00 & 9,09 & 53,92 & 17,97 & $\mathrm{P}$ \\
\hline Cinnamomum sellowianum Angely & 888,89 & 7,08 & 0,795 & 16,29 & 0,67 & 6,06 & 29,43 & 9,81 & CS \\
\hline Solanum variabile Mart. & 1111,11 & 8,85 & 0,413 & 8,47 & 0,67 & 6,06 & 23,38 & 7,79 & $\mathrm{P}$ \\
\hline $\begin{array}{l}\text { Grazielia serrata (Spr.) R. M. King \& } \\
\text { H. Rob. }\end{array}$ & 666,67 & 5,31 & 0,239 & 4,91 & 1,00 & 9,09 & 19,31 & 6,44 & $\mathrm{P}$ \\
\hline Baccharis uncinella DC. & 555,56 & 4,42 & 0,096 & 1,98 & 1,00 & 9,09 & 15,49 & 5,16 & $\mathrm{P}$ \\
\hline $\begin{array}{l}\text { Cinnamomum amoenum (Nees) } \\
\text { Kosterm. }\end{array}$ & 444,44 & 3,54 & 0,193 & 3,96 & 0,67 & 6,06 & 13,56 & 4,52 & CS \\
\hline $\begin{array}{l}\text { Araucaria angustifolia (Bertol.) } \\
\text { Kuntze }\end{array}$ & 333,33 & 2,65 & 0,233 & 4,78 & 0,67 & 6,06 & 13,50 & 4,50 & $\mathrm{P}$ \\
\hline Asclepias sp. & 777,78 & 6,19 & 0,073 & 1,51 & 0,33 & 3,03 & 10,73 & 3,58 & $\mathrm{P}$ \\
\hline Prunus sellowii Koehne & 222,22 & 1,77 & 0,019 & 0,38 & 0,67 & 6,06 & 8,21 & 2,74 & $\mathrm{CL}$ \\
\hline Solanum verbascifolium C. B. Wright & 222,22 & 1,77 & 0,060 & 1,22 & 0,33 & 3,03 & 6,02 & 2,01 & $\mathrm{P}$ \\
\hline $\begin{array}{l}\text { Myrsine coriacea (Sw.) R. Br. ex } \\
\text { Roem. }\end{array}$ & 222,22 & 1,77 & 0,024 & 0,49 & 0,33 & 3,03 & 5,29 & 1,76 & $\mathrm{P}$ \\
\hline Myrcianthes gigantea D. Legrand & 222,22 & 1,77 & 0,002 & 0,05 & 0,33 & 3,03 & 4,85 & 1,62 & CS \\
\hline
\end{tabular}




\begin{tabular}{|c|c|c|c|c|c|c|c|c|c|}
\hline Eugenia pluriflora DC. & 111,11 & 0,88 & 0,037 & 0,76 & 0,33 & 3,03 & 4,67 & 1,56 & $\mathrm{CS}$ \\
\hline Clethra scabra Pers. & 111,11 & 0,88 & 0,026 & 0,54 & 0,33 & 3,03 & 4,45 & 1,48 & $\mathrm{CL}$ \\
\hline Ilex paraguariensis A. St.-Hil. & 111,11 & 0,88 & 0,018 & 0,37 & 0,33 & 3,03 & 4,28 & 1,43 & CS \\
\hline Mimosa scabrella Benth. & 111,11 & 0,88 & 0,009 & 0,18 & 0,33 & 3,03 & 4,10 & 1,37 & $\mathrm{P}$ \\
\hline Schinus terebinthifolius Raddi & 111,11 & 0,88 & 0,002 & 0,05 & 0,33 & 3,03 & 3,96 & 1,32 & $\mathrm{CL}$ \\
\hline Drimys brasiliensis Miers & 111,11 & 0,88 & 0,002 & 0,04 & 0,33 & 3,03 & 3,95 & 1,32 & $\mathrm{CL}$ \\
\hline Ocotea puberula (Rich.) Nees & 111,11 & 0,88 & 0,002 & 0,04 & 0,33 & 3,03 & 3,95 & 1,32 & $\mathrm{CL}$ \\
\hline Total & 12555,54 & 99,95 & 4,878 & 100,01 & 10,98 & 99,99 & 299,97 & 100,01 & \\
\hline
\end{tabular}

A avaliação da densidade revelou que as áreas sob tratamentos apresentaram valores entre 10.400 a 17.000 indivíduos.ha ${ }^{-1}$ (Tabela 2).

Tabela 2. Densidade e área basal por hectare nos tratamentos de restauração de áreas de preservação permanentes.

Table 2. Density and basal area per hectare on the treatments of restoration of permanent preservation areas.

\begin{tabular}{lcc}
\hline Tratamentos & Densidade $\left(\mathbf{n} . \mathbf{h a} \mathbf{- 1}^{\mathbf{1}}\right)$ & Área basal $\left(\mathbf{m}^{\mathbf{2}} \mathbf{. h a} \mathbf{~}^{\mathbf{- 1}}\right)$ \\
\hline T0 - Abandono da área & $13111 \mathrm{ab}$ & $5,49 \mathrm{a}$ \\
T1 - Ativação do banco de sementes & $10444 \mathrm{ab}$ & $3,72 \mathrm{a}$ \\
T2 - Semeadura de Mimosa scabrella & $11666 \mathrm{ab}$ & $11,45 \mathrm{~b}$ \\
T3 - Aplicação de chuva de sementes & $17000 \mathrm{~d}$ & $5,00 \mathrm{a}$ \\
T4 - Instalação de poleiros artificiais & $14777 \mathrm{bcd}$ & $5,62 \mathrm{a}$ \\
T5 - Transposição de solo & $16333 \mathrm{~cd}$ & $7,26 \mathrm{a}$ \\
T6 - Plantio de enriquecimento & $12555 \mathrm{ab}$ & $4,88 \mathrm{a}$ \\
\hline
\end{tabular}

Médias seguidas da mesma letra não diferem estatisticamente pelo teste de Tukey ao nível de 5\% de probabilidade.

O tratamento com aplicação de chuva de sementes apresentou a maior densidade de plantas.ha ${ }^{-1}$ (17.000), mas não foi estatisticamente diferente dos tratamentos com transposição do solo (16.333 plantas. $\mathrm{ha}^{-1}$ ) e com instalação de poleiros artificiais, que resultou em 14.777 plantas.ha $^{-1}$.

Observa-se também que o plantio de mudas na forma de enriquecimento teve um desempenho apenas regular entre os tratamentos, resultando em uma densidade de 12.555 plantas.ha ${ }^{-1}$. Esse tratamento não se diferenciou estatisticamente do abandono da área, da ativação do banco de sementes e da semeadura direta de bracatinga, que se configuram como os tratamentos com pior desempenho quanto à densidade de plantas.

A avaliação da área basal.ha ${ }^{-1}$ mostrou que o tratamento com semeadura direta de Mimosa scabrella foi significativamente superior aos demais (Tabela 2), resultando em $11,45 \mathrm{~m}^{2} \cdot \mathrm{ha}^{-1}$. Esse fato pode ser atribuído à característica de Mimosa scabrella, espécie pioneira de rápido crescimento e elevada rusticidade. Os demais tratamentos apresentaram valores de área basal entre 3,72 e 7,26 $\mathrm{m}^{2} . \mathrm{ha}^{-1}$, mas não foram significativamente diferentes. Destaca-se que entre os tratamentos de pior desempenho estão a ativação do banco de sementes e o plantio de enriquecimento. A reduzida área basal.ha ${ }^{-1}$ no tratamento com plantio de enriquecimento pode ser explicada pelos reduzidos diâmetros dos indivíduos associados à baixa densidade. $\mathrm{Na}$ análise da tabela 1 observa-se que, entre as espécies plantadas no tratamento com enriquecimento, somente foram amostradas Araucaria angustifolia e Mimosa scabrella, denotando baixa sobrevivência das mudas plantadas e a pequena influência destas no resultado em área basal do tratamento. Esse fato mostra que, apesar desse tratamento ter resultado em valores de diversidade e riqueza entre as mais elevadas, não foram as mudas plantadas responsáveis pelo resultado, mas outras causas que poderão ser evidenciadas com a continuidade dos estudos.

A avaliação da composição fitossociológica entre os tratamentos mostrou que a riqueza de espécies e a diversidade foram maiores nos tratamentos com plantio de enriquecimento, aplicação de chuva de sementes e instalação de poleiros artificiais (Tabela 3). Esses três tratamentos têm como característica comum possibilitar o ingresso de propágulos ou mudas de origem externa na área em recuperação, evidenciando os efeitos benéficos em relação à riqueza e à diversidade. A aplicação de chuva de sementes permite que os propágulos capturados durante o ano sejam inseridos na área em restauração, prevendo um padrão fenológico sequencial da comunidade natural na área em restauração e 
possibilitando futuramente a atração, alimentação e manutenção da fauna ao longo de todo ano (REIS et al., 2003). Bechara (2006) considera que a transposição da chuva de sementes é a maneira mais eficiente de promover a conexão ou fluxo gênico da área em restauração com os remanescentes naturais mais próximos. Essa conexão, conforme Metzger (2003), deve ser atingida na restauração de uma área degradada e visa facilitar o fluxo de organismos, de todas as formas de vida e de propágulos, ou pelo menos aproximá-los ao máximo possível, mais geneticamente do que apenas fisicamente.

$\mathrm{O}$ efeito dos poleiros artificiais na riqueza e diversidade de espécies deve-se ao abrigo que oferecem para aves e morcegos, que, por sua vez, transportam sementes dos fragmentos vegetacionais vizinhos, formando núcleos de diversidade que, num processo sucessional, atraem outras espécies animais e vegetais (REIS et al., 2003). O efeito desse tratamento pode ser notado não só localmente, ao seu redor, como também na paisagem, já que as aves trafegam no espaço aéreo, de poleiro em poleiro, até o fragmento mais próximo, deixando no caminho, enquanto voam ou quando pousam, uma série de propágulos (BECHARA, 2006). De forma semelhante, na transposição do solo, o banco de sementes concebe a capacidade de regeneração natural das populações pela presença de espécies nativas pioneiras capazes de fazer uma rápida cobertura do solo e iniciar o processo sucessional (VIEIRA, 2004). É considerada uma técnica excelente para a introdução de espécies colonizadoras, como plantas ruderais, ervas e arbustos pioneiros, anemocóricas e anemofílicas, que são as primeiras a gerar populações em áreas degradadas, pois não necessitam de animais para a sua dispersão (REIS; ZAMBONIM; NAKAZONO, 1999).

Por outro lado, os tratamentos com abandono da área e ativação do banco de sementes mostraram-se menos eficientes, pois resultaram nos menores valores de diversidade e riqueza de espécies. Os resultados sugerem que o uso anterior da área, com reflorestamento de $P$. elliottii, reduziu consideravelmente o banco de sementes no solo e consequentemente a sua resiliência, motivo pelo qual os tratamentos que se caracterizaram pelo ingresso de diásporos tiveram resultados melhores. Nesse sentido, alguns autores (HARPER, 1977; UHL et al., 1982; WHITMORE, 1984) já observaram que a velocidade e direção do processo de regeneração natural de determinada área está condicionada ao tipo de impacto inicial e também a outros fatores determinantes. Entre esses fatores, foram citados as plântulas e brotações presentes na área, o banco de sementes presentes no solo e as sementes introduzidas na área.

Bechara (2006), em uma análise de tratamentos para restauração em área de Cerrado, após a extração de povoamento de Eucalyptus sp., concluiu que o abandono da área mostrou-se mais eficiente, ocasionado pela elevada resiliência dos cerrados. Por outro lado, Aubert; Oliveira-Filho (1994), estudando a regeneração em sub-bosques sob plantios de Eucalyptus spp. e Pinus spp. em Minas Gerais, constataram que existe uma similaridade na fisionomia desse tipo de sub-bosque de acordo com a distância das fontes de diásporos. Nesse sentido, Andrade et al. (2002) salientaram que a distância da fonte de diásporos é uma das principais dificuldades enfrentadas pelas espécies no processo de colonização e estabelecimento, particularmente em áreas degradadas. Esse aspecto também foi salientado por Alvarenga et al. (2006), quando afirmaram que é de grande importância no processo de recuperação de uma área através da condução da regeneração natural, além do isolamento dela das fontes de degradação, a existência de fontes de diásporos nas suas proximidades.

A análise da porcentagem de espécies climácicas presentes nas áreas dos tratamentos mostrou resultados semelhantes (Tabela 3). A instalação de poleiros artificiais, a transposição de solo e o plantio de enriquecimento foram os tratamentos que resultaram em valores mais elevados de espécies climácicas. Esse fato confirma a eficiência dos três tratamentos acima no ingresso de espécies na área, especialmente daquelas tolerantes à sombra. $\mathrm{O}$ tratamento com ativação do banco de sementes no solo apresentou o menor valor em porcentagem de espécies climácicas, evidenciando que ele pode ter beneficiado mais intensamente as espécies pioneiras presentes no solo e que a participação das espécies climácicas no banco de sementes no solo é baixa, considerando-se que a ocupação anterior da área era com reflorestamento de pinus. Essa constatação de que as sementes estocadas no solo podem ser um importante mecanismo de controle da regeneração natural da vegetação, representando um depósito de elevada densidade, com ampla riqueza de espécies em estado de latência, sobretudo de espécies pioneiras e secundárias iniciais, é reforçada pelas considerações de Uhl et al. (1981), Garwood (1989) e PinãRodrigues et al. (1990).

Em outros estudos para avaliação da regeneração natural em áreas degradadas (PINTO 2001; COSTA, 2004; ALVARENGA et al., 2006), as espécies com maior índice de regeneração natural 
pertenciam ao grupo ecológico das pioneiras e climácicas exigentes de luz, resultados considerados esperados, uma vez que as principais espécies colonizadoras de grandes clareiras pertencem a esses grupos ecológicos.

Tabela 3. Diversidade de Shannon, riqueza de espécies e porcentagem de espécies climácicas nos tratamentos para restauração de áreas de preservação permanente situadas na empresa Renova Floresta, em Rio Negrinho (SC).

Table 3. Diversity of Shannon, riches of species and percentage of climax species on the treatments for the restoration of permanent preservation areas in Renova Floresta Company at Rio Negrinho (SC).

\begin{tabular}{lccc}
\hline Tratamentos & $\begin{array}{c}\text { Diversidade } \\
\left(\mathbf{H}^{\prime}\right)\end{array}$ & $\begin{array}{c}\text { Riqueza } \\
\left(\mathbf{n}^{\mathbf{0}} \text { de espécies }\right)\end{array}$ & $\begin{array}{c}\text { Espécies climácicas } \\
(\boldsymbol{\%})\end{array}$ \\
\hline T0 - Abandono da área & 1,9133 & 14 & 12 \\
T1 - Ativação do banco de sementes & 1,8782 & 11 & 4 \\
T2 - Semeadura de Mimosa scabrella & 2,0894 & 16 & 12 \\
T3 - Aplicação de chuva de sementes & 2,2318 & 17 & 11 \\
T4 - Instalação de poleiros artificiais & 2,5462 & 18 & 30 \\
T5 - Transposição de solo & 2,2676 & 16 & 20 \\
T6 - Plantio de enriquecimento & 2,3065 & 20 & 21 \\
\hline
\end{tabular}

A avaliação conjunta das variáveis densidade, área basal, diversidade, riqueza de espécies e porcentagem de espécies climácicas, realizada através da análise de agrupamentos, resultou em quatro grupos de tratamentos (Figura 1).

O primeiro agrupamento foi formado unicamente pelo tratamento com semeadura direta de Mimosa scabrella, que se diferenciou dos demais em consequência especialmente da área basal (Tabela 2). O segundo agrupamento foi formado pelos tratamentos de abandono da área e ativação do banco de sementes, que apresentaram os mais baixos valores de riqueza e diversidade. $\mathrm{O}$ tratamento com ativação do banco de sementes apresentou os mais baixos valores em todas as variáveis analisadas, evidenciando a baixa resiliência da área.

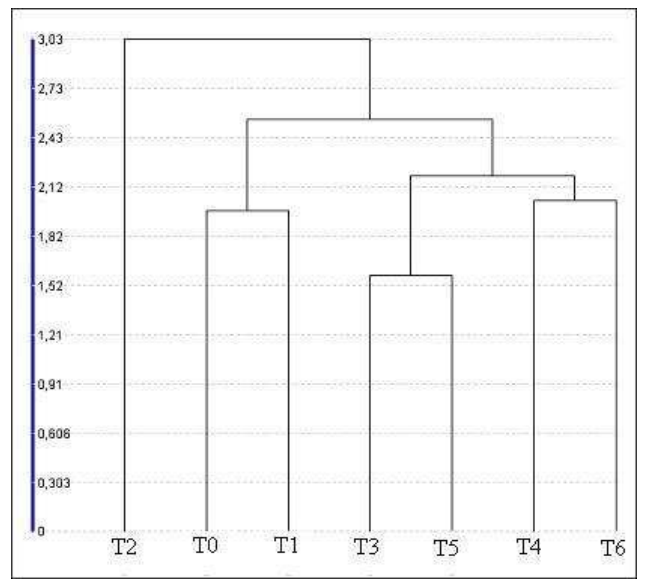

Figura 1. Dendrograma com os agrupamentos dos tratamentos de restauração da vegetação natural em áreas de preservação permanente da empresa Renova Floresta, em Rio Negrinho (SC). T0 abandono da área; T1 - ativação do banco de sementes; T2 - semeadura direta de Mimosa scabrella; T3 - aplicação de chuva de sementes; T4 - instalação de poleiros artificiais; T5 transposição de solo; T6 - plantio de enriquecimento.

Figure 1. Dendrogram with the grouping of the restoration of natural vegetation treatments in permanent preservation areas on the Renova Floresta Company at Rio Negrinho (SC). T0 - Control - Area Abandonment; T1 - Activation of seed bank in the soil; T2 - direct-seeding of Mimosa scabrella; T3 - application of seed rain; T4 - Installation of artificial perches; T5 - Soil transposition; T6 - Enrichment planting. 
O terceiro agrupamento foi formado pela aplicação de chuva de sementes e pela transposição de solo. Esses tratamentos apresentaram os valores de densidade mais elevados, mas mostraram valores intermediários entre as demais variáveis.

O quarto agrupamento foi formado pelos tratamentos de instalação de poleiros artificiais e de plantio de enriquecimento e teve os valores mais elevados de diversidade, riqueza de espécies e porcentagem de espécies climácicas.

Os agrupamentos resultantes mostraram uma clara distinção entre tratamentos que tiveram o ingresso induzido de plantas ou diásporos externos e aqueles que foram baseados somente na resiliência da área. As variáveis que contribuíram para essa distinção foram diversidade, riqueza de espécies e densidade de indivíduos, que se mostraram mais expressivas nos tratamentos aplicação de chuva de sementes, instalação de poleiros artificiais, transposição de solo e plantio de enriquecimento. Dessa forma, pode-se considerar essas três variáveis como as mais importantes na definição de métodos para restauração ecológica.

Esses resultados são convergentes com as observações de Pimm (1991) de que os métodos de nucleação aumentam a resiliência ambiental, pois o seu processo restaurador se baseia na ativação do próprio potencial de autorregeneração da comunidade. As técnicas nucleadoras de restauração formam micro-hábitats em núcleos onde são oferecidas, para as diferentes formas de vida, condições de abrigo, alimentação e reprodução, que num processo de aceleração sucessional irradiam diversidade por toda a área (REIS et al., 2003; BECHARA et al., 2005).

A distribuição dos indivíduos em classes de altura foi semelhante nos tratamentos abandono da área, ativação do banco de sementes, aplicação de chuva de sementes, instalação de poleiros artificiais e transposição de solo (Figura 2). Nesses tratamentos, a distribuição foi caracterizada pela maior concentração de indivíduos na classe entre 1,0 e 2,0 metros e pela quantidade de classes, que variou de 4 a 6. De forma geral, a distribuição nesses tratamentos apresentou tendência para distribuição normal.

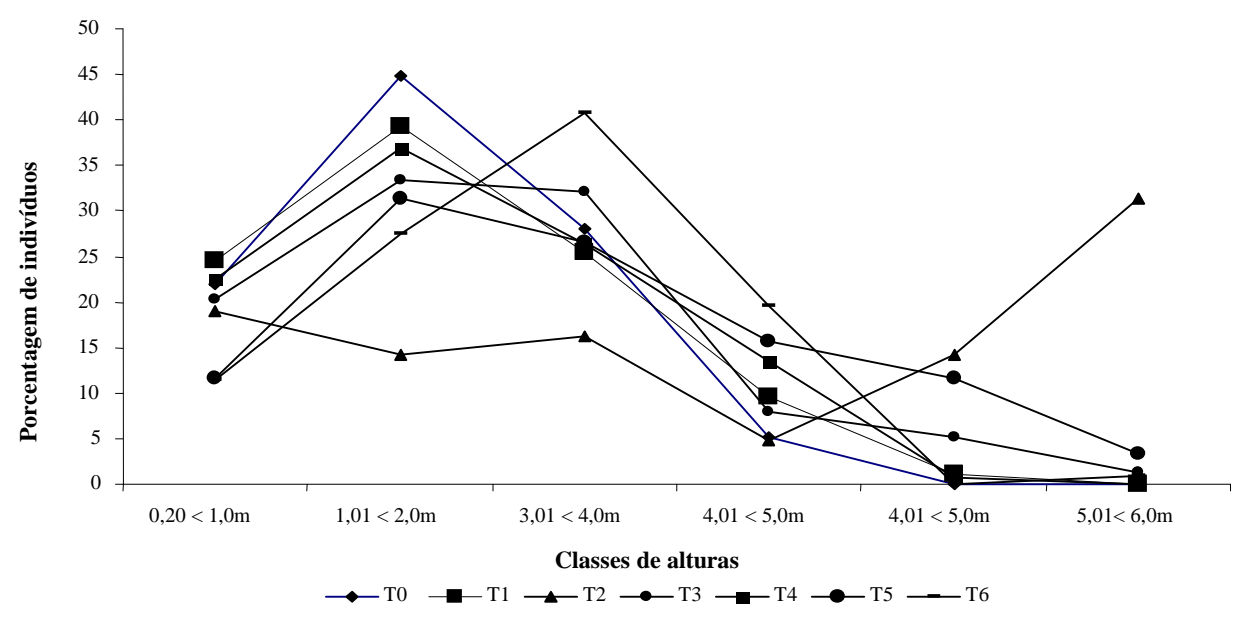

Figura 2. Distribuição dos indivíduos em classes de alturas nos tratamentos de restauração da vegetação natural em áreas de preservação permanente da empresa Renova Floresta, em Rio Negrinho (SC).

Figure 2. Distribution of the individuals in classes of height of the restoration of natural vegetation treatments in permanent preservation areas on the Renova Floresta at Rio Negrinho (SC).

No tratamento com semeadura de Mimosa scabrella, a distribuição foi ligeiramente crescente até a classe com indivíduos maiores de 5,0 metros. Essa distribuição mostra que Mimosa scabrella, além de apresentar a maior densidade (Tabela 1), também apresentou maior desenvolvimento em altura em relação às demais espécies.

A distribuição altimétrica no tratamento com plantio de enriquecimento também se diferenciou da distribuição nos demais tratamentos. A maior concentração de indivíduos foi verificada na classe entre 2,0 a 3,0 metros de altura, mostrando que, com exceção do tratamento com semeadura de M. scabrella, o 
desenvolvimento em altura foi ligeiramente superior nesse tratamento. Esse resultado pode ser explicado pelo próprio plantio de mudas, que em geral foram levadas a campo com alturas superiores a $50 \mathrm{~cm}$, antecipando-se em tamanho em relação aos tratamentos onde os indivíduos iniciaram o desenvolvimento a partir da germinação de sementes ou de plântulas recém-instaladas. Denota-se, assim, que a introdução de M. scabrella, através do plantio de mudas ou semeadura direta na área, eleva a altura média da vegetação regenerante, em função do crescimento mais rápido dessa espécie. Salienta-se que, no tratamento com plantio de enriquecimento, entre as espécies plantadas somente foram amostradas $A$. angustifolia e $M$. scabrella, evidenciando que a contribuição das mudas plantadas na diversidade e densidade de plantas foi pequena, em função da sua baixa sobrevivência, como já mencionado anteriormente.

\section{CONCLUSÕES}

- Solanum variabile, Baccharis uncinella e Eupatorium compressun, espécies não-arbóreas, foram as de maior frequência, densidade e importância na maioria dos tratamentos aplicados, sendo pouco influenciadas por esses tratamentos.

- Os tratamentos de condução da regeneração natural, que incluem o ingresso de diásporos, como é o caso de aplicação de chuva de sementes, transposição de solo e instalação de poleiros artificiais, resultaram em densidades mais elevadas de plantas.

- A riqueza de espécies e a diversidade foram maiores nos tratamentos com plantio de enriquecimento, aplicação de chuva de sementes e instalação de poleiros artificiais.

- Nos tratamentos com semeadura de Mimosa scabrella e plantio de enriquecimento, foram obtidas maiores alturas dos indivíduos.

- Foi possível identificar quatro agrupamentos de tratamentos. O agrupamento contendo a instalação de poleiros artificiais e plantio de enriquecimento apresentou os valores mais elevados de diversidade, riqueza de espécies e porcentagem de espécies climácicas.

- Entende-se como variáveis mais adequadas para a avaliação da restauração ecológica a densidade, a diversidade e a riqueza de espécies, pois contribuíram de forma consistente para segregar as técnicas analisadas.

\section{REFERÊNCIAS}

ALVARENGA, A. P.; BOTELHO, S. A.; PEREIRA, I. M. Avaliação da regeneração natural na recomposição de matas ciliares em nascentes na região sul de Minas Gerais. Lavras: Cerne, v. 12, n. 4, p. 360-372, 2006.

ANDRADE, L. A.; PEREIRA, I. M.; DORNELA, G. V. Análise da vegetação arbóreo-arbustiva, espontânea, ocorrente em taludes íngremes no município de Areia - estado da Paraíba. Revista Árvore, Viçosa, v. 26, n. 2, p. 165-172, 2002.

AUBERT, E.; OLIVEIRA FILHO, A. T. Análise multivariada da estrutura fitossociológica do sub-bosque de plantios experimentais de Eucalyptus spp. e Pinus spp em Lavras, MG. Lavras: UFLA, 1994.

BARDDAL, M. L. Aspectos florísticos e fitossociológicos do componente arbóre-arbustivo de uma Floresta Ombrófila Mista Aluvial - Araucária, PR. 2002. 90 f. Dissertação (Mestrado em Ciências Florestais) - Setor de Ciências Agrárias, Universidade Federal do Paraná, Curitiba, 2002.

BARDDAL, M. L.; RODERJAN, C. V.; GALVÃO, F.; CURCIO, G. R. Fitossociologia do sub-bosque de uma Floresta Ombrófila Mista Aluvial, no município de Araucária, PR. Santa Maria: Ciência Florestal, v. 14, n. 1, p. 35-45, 2004.

BECHARA, F. C. Unidades demonstrativas de restauração ecológica através de técnicas nucleadoras: Floresta Estacional Semidecidual, Cerrado e Restinga. Piracicaba: 2006. Tese - Escola Superior de Agricultura Luiz de Queiroz. Universidade de São Paulo. 
BECHARA, F. C.; CAMPOS FILHO, E. M.; BARRETO, K. D.; ANTUNES, A. Z.; REIS, A. Nucleação de diversidade ou cultivo de árvores nativas? In: SIMPÓSIO NACIONAL E CONGRESSO LATINOAMERICANO SOBRE RECUPERAÇÃO DE ÁREAS DEGRADADAS. Curitiba. Anais... Curitiba: Sociedade Brasileira de Recuperação de áreas Degradadas, 2005. p. 355-363.

BOTELHO, S. A.; DAVIDE, A. C. Métodos silviculturais para recuperação de nascentes e recomposição de matas ciliares. In: SIMPÓSIO NACIONAL SOBRE RECUPERAÇÃO DE ÁREAS DEGRADADAS, 5, 2002, Belo Horizonte. Anais... Belo Horizonte: UFMG, 2002. p. 123-145.

BRASIL. Lei Federal n. ${ }^{\circ} 4.771$, de 15 de setembro de 1965. Institui o Novo Código Florestal Brasileiro. Diário oficial da República Federativa do Brasil, Brasília, DF, 12 jan. 2009. Disponível em:<http:// www.mma.gov.br/estruturas/sbf2008_dap/_legislacao/149_legislacao12012009045054.pdf> Acesso em 15 de julho de 2009.

BROWER, J. E.; ZAR, J. H. Field and Laboratory methods for general ecology. Dubuque: W. M. C. Brow, 1984. $226 \mathrm{p}$.

COSTA, S. S. B. Estudo da bacia do Ribeirão Jaguará, MG, como base para o planejamento da conservação e recuperação das nascentes e matas ciliares. 2004. 214 p. Dissertação (Mestrado em Engenharia Florestal) - Universidade Federal de Lavras, Lavras, 2004.

EMPRESA BRASILEIRA DE PESQUISA AGROPECUÁRIA (EMBRAPA). Sistema brasileiro de classificação de solos. Brasília: Embrapa Produção de Informação, Rio de Janeiro, Embrapa Solos, 1999. 412 p.

FINOL, H. Nuevos parametros a considerar-se en la análisis estructural de las selvas virgenes tropicales. Revista Forestal Venezolana. v. 14, n. 21, p. 29-42. 1971.

GAPLAN. Atlas de Santa Catarina. Aerofoto Cruzeiro. Rio de Janeiro. 1986. 173 p.

GARWOOD, N. C. Tropical soil seed banks: a rewiew. In: LECK, M.; PARKER, V.; SIMPSON, R. (org.). Ecology of soil seed banks. San Diego: Academia Press, 1989. p. 149-209.

HARPER, J. L. Population biology of plants. New York: Academia, 1977. 892 p.

KOBIYAMA, M.; CHECCHIA, T.; CORSEUIL, C. W.; LINO, J. F. L.; LOPES, N. H. Y.; GRISON, F.; CHAFFE, P. L. B.; MALUTTA, S.; RIBAS JUNIOR, U.; LANGA, R.; BASSO, S. Forest hydrology project (UFSC-MOBASA) for water resources management in Rio Negrinho City, Santa Catarina, Brazil. In: VAN de GIESEN, XIA, J.; ROSBJERG, D.; FUKUSHIMA, Y. (eds.). Changes in Water Resources Systems: Methodologies to Maintain Water Security and Ensure Integrated Management, Wellington: IAHS, 2007. p. 250-257. (IAHS Publication 315).

METZGER, J. P. Como restaurar a conectividade de paisagens fragmentadas? In: KAGEYAMA, P. Y; OLIVEIRA, R. E.; MORAES, L. F. D.; ENGEL, V. L.; GANDARA, F. B. (orgs.). Restauração ecológica de ecossistemas naturais. São Paulo: FEPAF, 2003. p. 49-76.

OLIVEIRA-FILHO, A. T. Estudos ecológicos da vegetação como subsídio para programas de revegetação com espécies nativas: uma proposta metodológica. Cerne, v. 1, n. 1, p. 64-72, 1994.

PIMM, S. L. The balance of nature? Ecological issues in the Conservation of species and communities. Chicago: University Press, 1991. 434 p.

PIÑA-RODRIGUES, F. C. M.; COSTA, L. G. S.; REIS, A. Estratégias de estabelecimento de espécies arbóreas e o manejo de florestas tropicais. In: CONGRESSO FLORESTAL BRASILEIRO, 6, 1990, Campos do Jordão. Anais... Campos do Jordão: Editora, 1990. p. 676-683.

PINTO, L. V. A. Caracterização física da sub-bacia do ribeirão Santa Cruz, Lavras, MG: proposta de recuperação de suas nascentes. 2003. 165 p. Dissertação (Mestrado em Engenharia Florestal) Universidade Federal de Lavras. Lavras, 2003.

REIS, A. Sucessão. In: Curso de restauração de áreas degradadas: imitando a natureza. Florianópolis: 2006. 83 p. 
REIS, A.; BECHARA, F. C.; ESPÍNDOLA, M. B.; VIEIRA, N. K.; SOUZA, L. L. Restauração de áreas degradadas: a nucleação como base para incrementar os processos sucessionais. Natureza \& Conservação, Curitiba, v. 1, n. 1, p. 28-36, 85-92. 2003.

REIS, A.; ZAMBONIM, R. M.; NAKAZONO, E. M. Recuperação de áreas florestais degradadas utilizando a sucessão e as interações planta animal. Série Cadernos da Biosfera, São Paulo, n. 14, p. 1-42, 1999.

RODRIGUES, R. R.; GANDOLFI, S. Conceitos, tendências e ações para a recuperação de florestas ciliares. In: RODRIGUES, R. R.; LEITÃO FILHO, H. F. (eds.) Matas ciliares: conservação e recuperação. São Paulo: Editora da Universidade de São Paulo/FAPESP. 2000. p. 241-243.

SWAINE, M. D.; WHITMORE, T. C. On the definition of ecological species groups in tropical rain forest. Vegetatio, The hague, v. 75, n. 2, p. 81-86, 1988.

UHL, C.; CLARK, H.; CLARK, K. Successional patterns associated with slash and burn agriculture in upper Rio Negro region of the Amazon Basin. Biotropica, v. 14, n. 4, p. 249-254, 1982.

UHL, C.; CLARK, K.; CLARK, H.; MURPHY, P. Early plant succession after cutting and burning in the upper Rio Negro region on the Amazonian Basin. Journal of Ecology, v. 69, p. 631-649, 1981.

VIEIRA, N. K. O papel do banco de sementes na restauração de restinga sob talhão de Pinus elliottii Engelm. 2004. 77 p. Dissertação (Mestrado em Biologia Vegetal) - Universidade Federal de Santa Catarina, Florianópolis, 2004.

WHITMORE, T. C. Tropical rain forest dynamics on the far east. Oxford: Clarendon, 1984. 352 p.

YARRANTON, G. A.; MORRISON, R. G. Spatial dynamics of a primary succession: nucleation. Journal of Ecology, Oxford, v. 62, n. 2, p. 417-428, 1974. 
